\title{
ISCHAEMIC STROKE - CLINICAL PROFILE AND EVALUATION WITH ELECTROENCEPHALOGRAPHY AND MRI BRAIN
}

Sreenivasa Murthy L', Sreenivasa Rao Sudulagunta², Shiva Kumar Bangalore Raja ${ }^{3}$, Bhaktavatchalam ${ }^{4}$, Mahesh Babu Sodalagunta ${ }^{5}$, Mona Sepehrar6, Munawar Dhanish M7, Keshava Chandra Thejaswi ${ }^{8}$

\author{
1 Professor, Department of Medicine, Dr. B. R. Ambedkar Medical College. \\ ${ }^{2}$ Senior Resident in Internal Medicine, Department of Medicine, Dr. B. R. Ambedkar Medical College. \\ 3 Professor, Department of General Medicine, Dr. B. R. Ambedkar Medical College. \\ ${ }^{4}$ Professor and HOD, Department of General Medicine, Dr. B. R. Ambedkar Medical College. \\ ${ }_{5}^{5}$ Postgraduate Student, Department of General Medicine, Dr. B. R. Ambedkar Medical College. \\ ${ }_{6}^{6}$ Pharm. D, Doctor of Pharmacy, Dr. B. R. Ambedkar Medical College. \\ 7Junior Resident, Department of General Medicine, Dr. B. R. Ambedkar Medical College. \\ 8Junior Resident, Department of General Medicine, Dr. B. R. Ambedkar Medical College.
}

ABSTRACT
BACKGROUND
Acute Ischaemic Stroke (AIS) is characterised by thrombotic or embolic occlusion of a cerebral artery. Electroencephalography (EEG)
is an electrophysiological monitoring method to record electrical activity of the brain measuring voltage fluctuations resulting
from ionic current within the neurons of the brain. Our study evaluated stroke with EEG and MRI Brain.

\section{MATERIALS AND METHODS}

Our cross-sectional study enrolled 150 patients of ischaemic stroke from July 2012 till July 2015 . A detailed study of 150 cases of ischaemic stroke with mode of presentation, Laboratory data, MRI scan and EEG features has been made.

\section{RESULTS}

Majority of patients are aged above 60 years. Regarding risk factors, 76\% (114) of patients had hypertension, 66\% (99) had diabetes mellitus, 62\% (93) were smokers and 42\% (63) had history of alcoholism; 105 patients (70\%) had abnormal total cholesterol level, 114 patients (76\%) had abnormal triglyceride levels and 117 patients (78\%) had abnormal HDL levels. Abnormal EEG was observed in 87 patients (58\%) out of a total of 150 patients, out of which 45 patients developed post stroke seizures.

\section{CONCLUSION}

Elderly individuals are at increased risk of stroke. Comorbidities and lipid abnormalities increase the risk significantly. MRI is the most useful investigation for diagnosis and management in ischaemic stroke. Abnormal EEG and generalised slowing pattern observed specifically are associated with complications and mortality after acute ischaemic stroke. Larger infarct volume is associated with higher delta power in EEG.

\section{KEYWORDS}

Ischaemic Stroke, Encephalography, MRI Brain, Periodic Lateralised Epileptiform Discharges.

HOW TO CITE THIS ARTICLE: Murthy SL, Sudulagunta SR, Raja SKB, et al. Ischaemic stroke - clinical profile and evaluation with electroencephalography and MRI brain. J. Evolution Med. Dent. Sci. 2016;5(103):7509-7514, DOI: 10.14260/jemds/2016/1700

\section{BACKGROUND}

Acute Ischaemic Stroke (AIS) is characterised by the sudden loss of circulation to an area of the brain, resulting in loss of neurologic function corresponding to it. It was previously known Cerebrovascular Accident (CVA) or stroke syndrome. Stroke is a nonspecific state of neuronal dysfunction with brain injury associated with several pathophysiologic causes. Strokes are divided into 2 types: haemorrhagic and ischaemic. Acute Ischaemic Stroke (AIS) is characterised by thrombotic or embolic occlusion of a cerebral artery. Ischaemic and haemorrhagic stroke cannot be clearly differentiated only on

Financial or Other, Competing Interest: None.

Submission 07-12-2016, Peer Review 19-12-2016,

Acceptance 21-12-2016, Published 26-12-2016.

Corresponding Author:

Dr. Sreenivasa Murthy L,

Professor,

Department of Medicine,

Dr. B. R. Ambedkar Medical College,

K. G. Halli, Bangalore-560045.

E-mail: drsreenivasamurthy@gmail.com

DOI: $10.14260 /$ jemds $/ 2016 / 1700$ the basis of clinical examination findings, as there is considerable overlap of clinical features. Evaluation with Computed Tomography [CT] scanning or Magnetic Resonance Imaging [MRI] is required.

Stroke is a major cause of disability and the fifth leading cause of death in the United States.[1],[2] Each year in the United States, about 795,000 people experience new $(610,000)$ or recurrent $(185,000)$ stroke. [3] Epidemiologic studies indicate that $82 \%-92 \%$ of strokes in the USA are ischaemic. Stroke was the second most common cause of death globally in 2011, causing 6.2 million deaths $(\sim 11 \%$ of the total).[4] Approximately, 17 million people suffered a stroke in 2010 and 33 million people have previously had a stroke and were still alive.[5] Between the years 1990 and 2010, the number of strokes decreased by $10 \%$ in the developed world and increased by $10 \%$ in the developing world approximately.[5]

A total of two-thirds of strokes occurred in individuals over the age of 65 years.[5] South Asians are at increased risk of stroke, accounting for $40 \%$ of stroke deaths worldwide.[6] The incidence of stroke increases from 30 years of age and the aetiology varies with age.[7] Men have $25 \%$ higher chance of 
suffering from strokes than women. ${ }^{[8]}$ However, $60 \%$ of deaths from stroke occur in women as they live longer, and are older on average at stroke onset. Important risk factors in women are pregnancy, childbirth, menopause and hormone replacement.

Acute occlusion of an intracranial vessel causes reduction in blood flow to the brain region it supplies. The magnitude of flow reduction is a function of collateral blood flow and this depends on individual vascular anatomy and the site of occlusion. A fall in cerebral blood flow to zero causes death of brain tissue within $4-10$ mins; values $<16-18 \mathrm{~mL} / 100 \mathrm{~g}$ tissue per min cause infarction within an hour; and values $<20$ $\mathrm{mL} / 100 \mathrm{~g}$ tissue per min cause ischaemia without infarction unless prolonged for several hours or days. If blood flow is restored prior to a significant amount of cell death, the patient may experience only transient symptoms, i.e. a TIA. Tissue surrounding the core region of infarction is ischaemic, but reversibly dysfunctional and is referred to as the ischaemic penumbra. The penumbra may be imaged by using perfusiondiffusion imaging with MRI.

Electroencephalography (EEG) is an electrophysiological monitoring method to record electrical activity of the brain measuring voltage fluctuations resulting from ionic current within the neurons of the brain. EEG was previously used as a first-line method of diagnosis for tumours, stroke and other focal brain disorders, but its use has decreased with the advent of Magnetic Resonance Imaging (MRI) and Computed Tomography (CT). In the present study, an endeavour is made to document the cases of Ischaemic Stroke and an effort is made to elucidate EEG findings and aetiological factors. A detailed study of 150 cases of Ischaemic Stroke with mode of presentation, laboratory data, MRI scan, EEG features has been made. Detailed analysis of results done.

\section{MATERIALS AND METHODS}

Our cross-sectional study enrolled 150 patients of ischaemic stroke from July 2012 till July 2015. Even though 183 patients were initially enrolled, 33 patients were lost for followup and did not get all the investigations, hence excluded. Complete history and examination of patients was documented. Investigations including complete haemogram, renal function tests, MRI brain, lipid profile, chest x-ray, ECG and EEG were done. All patients will be treated with supportive therapy, antiplatelet agents and results were tabulated. Results were discussed later in correlation with other studies. EEG and MRI brain results during diagnosis and followup were correlated to clinical condition. EEG was done at initial presentation of patient at emergency medicine, ICU or medical ward during discharge and followup.

\section{Inclusion Criteria}

1. Patients from age group above 18 yrs. and below 80 yrs. with clinical features suggestive of stroke.

2. Patients with sudden onset of loss of consciousness where MRI brain is suggestive of stroke.

3. Patients with hemiparesis with or without loss of consciousness and MRI brain showing ischaemic changes.

4. Patients with recent onset of other focal neurological deficits with MRI brain showing evidence of stroke.
5. Patients with clinical features of hemiparesis, neurological deficits without any evidence in initial MRI scan.

\section{Exclusion Criteria}

1. Recent head injury (less than 6 weeks).

2. Epileptic disorders.

3. Recurrent stroke.

4. Mental retardation and structural abnormalities of brain.

5. Neuro-infections (TB meningitis, Bacterial meningitis, etc.)

6. Pregnant women.

7. Strokes more than 7 days' duration.

8. Age less than 18 or more than 80 yrs.

\section{RESULTS}

Out of 150 patients enrolled in the study males constituted $72 \%$ of patients, while females constituted $28 \%$ of patients [Table 1, Figure 1]. Regarding age distribution of patients, $40 \%$ of patients were in the age group of 60 - 69 years followed by $24 \%$ of patients in the age group of $50-59$ years, followed by $14 \%$ of patients in the age group of $40-49$ years. The results of age distribution are represented in Table 2 and Figure 2. Regarding the mode of onset, $90 \%$ of patients had sudden onset of symptoms, while $10 \%$ had gradual onset of symptoms [Figure 3].

Regarding risk factors $76 \%$ (114) of patients had hypertension, 66\% (99) had diabetes mellitus, 62\% (93) were smokers and $42 \%$ (63) had history of alcoholism [Table 3, Figure 4]. Regarding abnormalities in lipid profile, 105 patients $(70 \%)$ had abnormal total cholesterol level, 114 patients $(76 \%)$ had abnormal triglyceride levels, 117 patients (78\%) had abnormal HDL levels [Table 4, Figure 5]. Regarding pattern of weakness, 105 patients $(70 \%)$ had left hemiparesis, while 45 patients $(30 \%)$ had right hemiparesis [Table 5 , Figure 6].

Regarding site of arterial infarction 111 patients (74\%) had middle cerebral artery involvement, 54 patients $(36 \%)$ has posterior cerebral artery involvement, 39 patients (26\%) had anterior cerebral artery involvement and 24 patients (16\%) had combined arterial involvement. Regarding family history of risk factors, 45 patients (30\%) had family history of hypertension, 39 patients (26\%) had family history of diabetes mellitus, 18 patients $(12 \%)$ had family history of stroke and 15 patients $(10 \%)$ had family history of coronary heart disease. EEG in stroke:

Abnormal EEG was observed in 87 patients (58\%) out of a total of 150 patients, out of which 45 patients developed post stroke seizures. Abnormal EEG was more common in patients aged more than 50 years compared to patients aged below 50 years $(p<0.001)$. Overall, the commonest EEG abnormality was focal slowing observed in 41 out of 87 patients (47.12\%) with EEG abnormalities. In the patients who had abnormal EEG and generalised slowing, the association of complications is higher compared to other groups. Larger infarct volume observed in MRI brain was associated with higher delta power in EEG bilaterally.

A total of 45 patients ( $30 \%)$ had post stroke seizures. Mean age was 64.6 years; $37.7 \%(n=17)$ patients were in awake state, $28.8 \%(n=13)$ patients were drowsy, $15.6 \%(n=7)$ were 
sedated, $11.11 \%(n=5)$ were semiconscious, $4.44 \%(n=2)$ were unconscious and $2.2 \%(n=1)$ was in asleep state. The most common seizure semiology observed was generalised seizures in $64.4 \%(n=29)$, focal seizures in $24.44 \%(n=11)$ and focal with secondary generalisation in $11.11 \%(n=5)$ patients; $66.7 \%(n=30)$ patients had right hemispheric involvement and $33.3 \%(n=15)$ had left hemispheric involvement.

The commonest EEG finding observed in post-stroke seizures was generalised slow waves seen in $40 \% \quad(n=18)$ patients. Other abnormalities observed were focal slowing in $20 \%(n=9)$, focal sharp and slow waves in $13.33 \%(n=6)$, focal spikes and slow waves in $6.67 \%(n=3)$, focal sharp waves in $6.67 \%(n=3)$ of the patients. Focal spike waves in $6.67 \%(n=3)$ and PLEDS were seen in $6.67 \%(n=3)$ patients [Figure 9].

\begin{tabular}{|c|c|c|}
\hline Gender & No. of Patients & Percentage \\
\hline Males & 108 & $72 \%$ \\
\hline Females & 42 & $28 \%$ \\
\hline \multicolumn{2}{|c|}{ Table 1. Gender Distribution in Study Group } \\
\hline
\end{tabular}

\begin{tabular}{|c|c|c|}
\hline Age & No. of Patients & Percentage \\
\hline $20-29$ yrs. & 6 & $4 \%$ \\
\hline $30-39$ yrs. & 12 & $8 \%$ \\
\hline $40-49$ yrs. & 21 & $14 \%$ \\
\hline $50-59$ yrs. & 36 & $24 \%$ \\
\hline $60-69$ yrs. & 60 & $40 \%$ \\
\hline $70-79$ yrs. & 15 & $10 \%$ \\
\hline \multicolumn{2}{|c|}{ Table 2. Age Distribution in Study Group } \\
\hline
\end{tabular}

\begin{tabular}{|c|c|c|}
\hline Risk Factor & No. of Patients & Percentage \\
\hline Diabetes Mellitus & 99 & $66 \%$ \\
\hline Hypertension & 114 & $76 \%$ \\
\hline Smoking & 93 & $62 \%$ \\
\hline Alcoholism & 63 & $42 \%$ \\
\hline \multicolumn{2}{|c|}{ Table 3. Risk Factors of Stroke in Patients } \\
\hline
\end{tabular}

\begin{tabular}{|c|c|c|}
\hline Lipid Abnormality & $\begin{array}{c}\text { No. of } \\
\text { Patients }\end{array}$ & Percentage \\
\hline $\begin{array}{c}\text { Total cholesterol } \geq 200 \\
\mathrm{mg} / \mathrm{dL}\end{array}$ & 105 & $70 \%$ \\
\hline $\begin{array}{c}\text { Triglycerides } \geq 150 \\
\mathrm{mg} / \mathrm{dL}\end{array}$ & 114 & $76 \%$ \\
\hline $\mathrm{HDL}<40$ & 117 & $78 \%$ \\
\hline
\end{tabular}

\begin{tabular}{|c|c|c|}
\hline Pattern & No. of Patients & Percentage \\
\hline Right Hemiparesis & 45 & $30 \%$ \\
\hline Left Hemiparesis & 105 & $70 \%$ \\
\hline \multicolumn{2}{|c|}{ Table 5. Pattern of Weakness in Study Population } \\
\hline
\end{tabular}

\begin{tabular}{|c|c|c|}
\hline Infarct Territory & No. of Patients & Percentage \\
\hline ACA & 39 & $26 \%$ \\
\hline MCA & 111 & $74 \%$ \\
\hline PCA & 54 & $36 \%$ \\
\hline ACA and MCA & 24 & $16 \%$ \\
\hline MCA and PCA & 24 & $16 \%$ \\
\hline ACA and PCA & 3 & $2 \%$ \\
\hline \multicolumn{2}{|c|}{ Table 6. Site of Arterial Infarction in Brain } \\
\hline
\end{tabular}

\begin{tabular}{|c|c|c|}
\hline Risk Factors & No. of Patients & Percentage \\
\hline Hypertension & 45 & $30 \%$ \\
\hline Diabetes Mellitus & 39 & $26 \%$ \\
\hline C.H.D & 15 & $10 \%$ \\
\hline C.V.A & 18 & $12 \%$ \\
\hline \multicolumn{2}{|c|}{ Table 7. Family History of Risk Factors } \\
\hline
\end{tabular}

\begin{tabular}{|c|c|c|}
\hline Variables & Number (\%) & P value \\
\cline { 1 - 2 } 50 - 79 years & $\begin{array}{c}80 / 111 \text { patients } \\
(72 \%)\end{array}$ & \multirow{2}{*}{0.0001} \\
$<50$ years & $\begin{array}{c}7 / 39 \text { patients } \\
(18 \%)\end{array}$ & \\
\cline { 1 - 2 } Focal slowing in EEG & $41 / 87$ & \multirow{2}{*}{0.1707} \\
\cline { 1 - 2 } $\begin{array}{c}\text { Generalised slowing in EEG } \\
\text { Generalised slowing and } \\
\text { complications }\end{array}$ & $31 / 87$ & \multirow{2}{*}{0.0206} \\
\cline { 1 - 2 } $\begin{array}{c}\text { Focal slowing and } \\
\text { complications }\end{array}$ & $7 / 31$ & \\
\cline { 1 - 2 } Table 8. EEG Abnormalities in Ischaemic Stroke \\
\hline
\end{tabular}

\begin{tabular}{|c|c|c|}
\hline Grade & $\begin{array}{c}\text { CBF } \\
(\mathbf{m L} / \mathbf{1 0 0 g} / \mathbf{m i n})\end{array}$ & EEG Changes \\
\hline 0 & $35-70$ & Normal \\
\hline I & $25-35$ & $\begin{array}{c}\text { Loss in faster beta } \\
\text { frequencies }\end{array}$ \\
\hline II & $18-25$ & $\begin{array}{c}\text { Slowing of background to 5 - } \\
7 \text { Hz (theta) }\end{array}$ \\
\hline III & $12-18$ & Slowing to 1 - 4 Hz (delta) \\
\hline IV & $<8-10$ & $\begin{array}{c}\text { Suppression of all } \\
\text { frequencies with neuronal } \\
\text { death (Cortical suppression) }\end{array}$ \\
\hline \multicolumn{2}{|c|}{ Table 9. EEG Abnormalities in Cerebral Ischaemia } \\
\hline
\end{tabular}

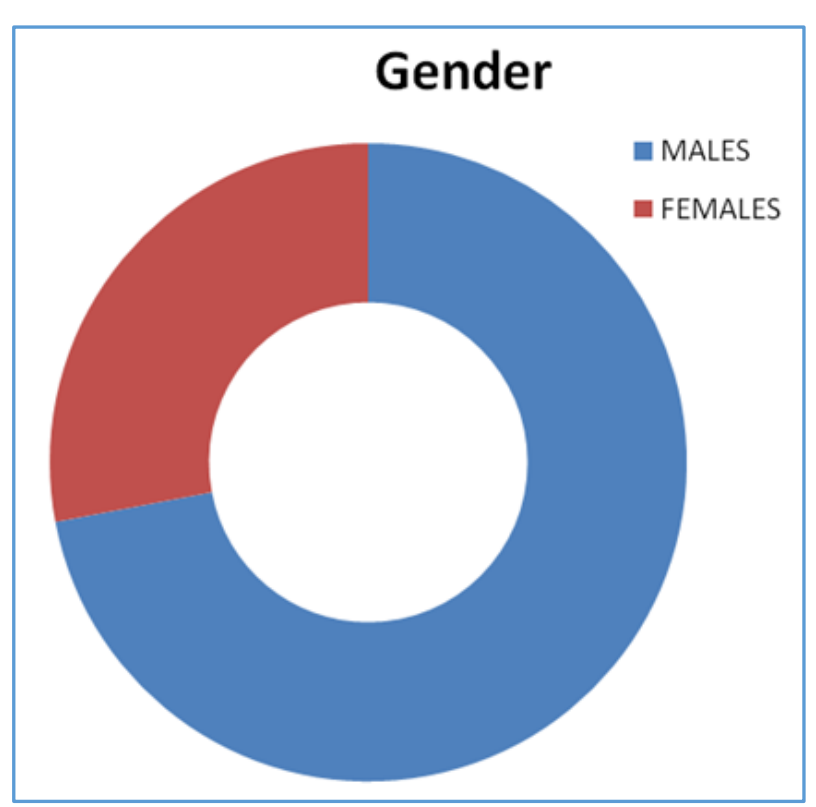

Figure 1. Gender Distribution in Study Group 


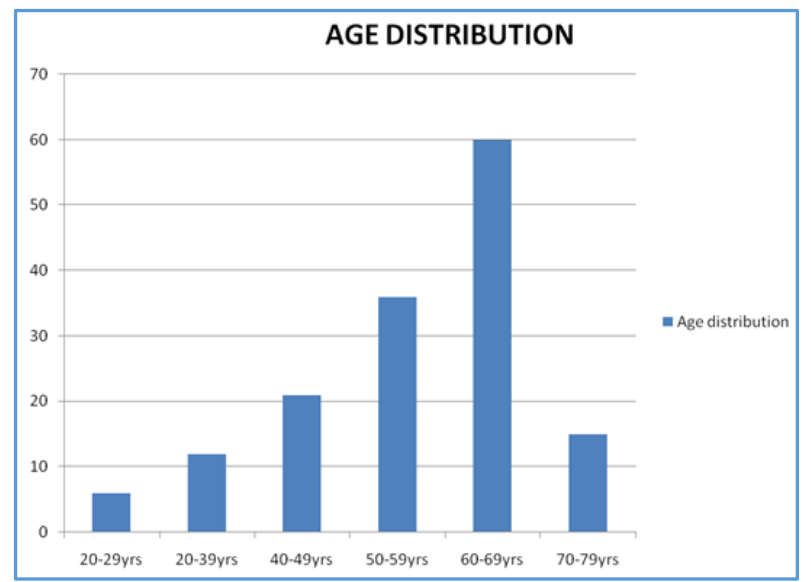

Figure 2. Age Distribution in Study Group

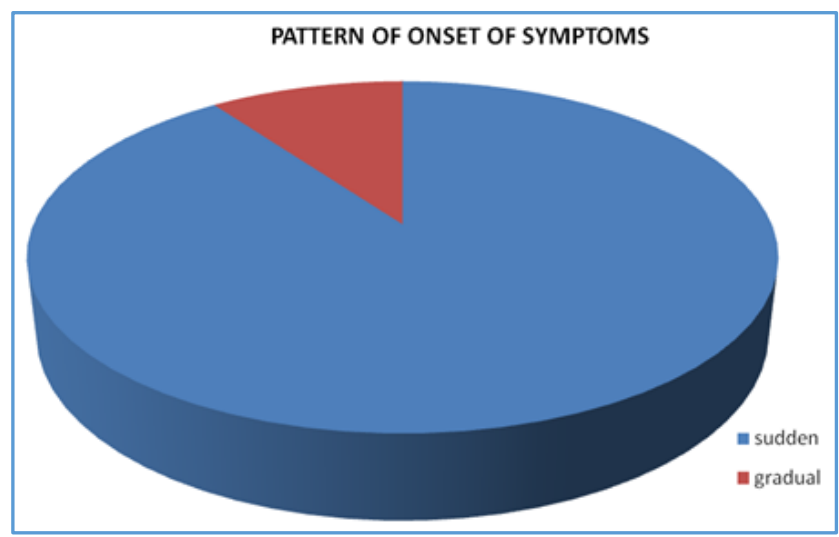

Figure 3. Pattern of Onset of Symptoms

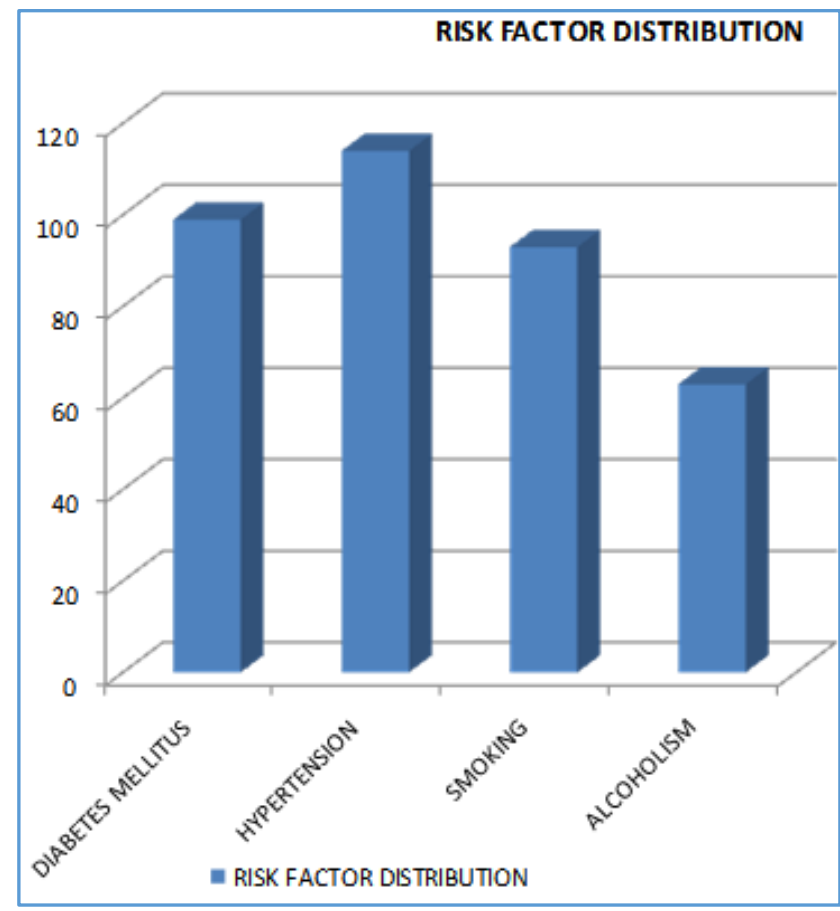

Figure 4. Risk Factor Distribution in Study Population

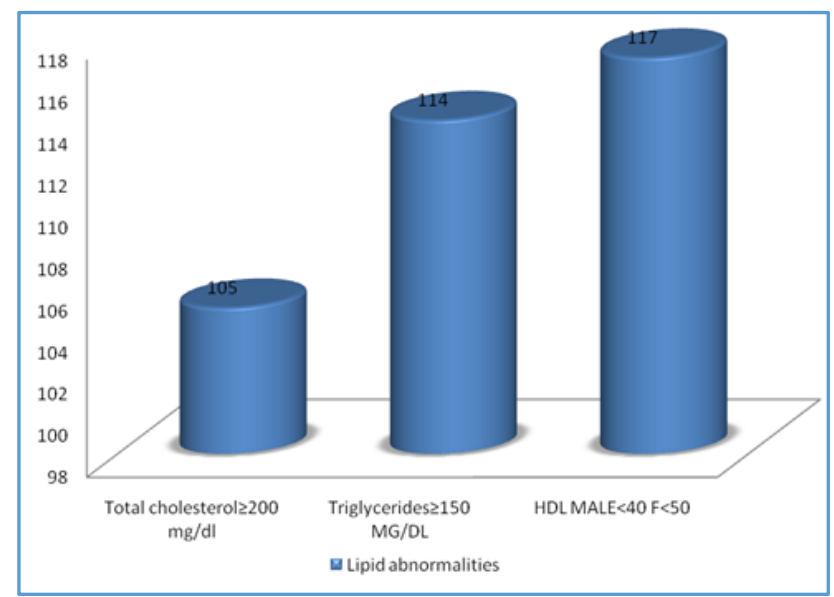

Figure 5. Abnormal Lipid Profile in Study Population (150 Patients)

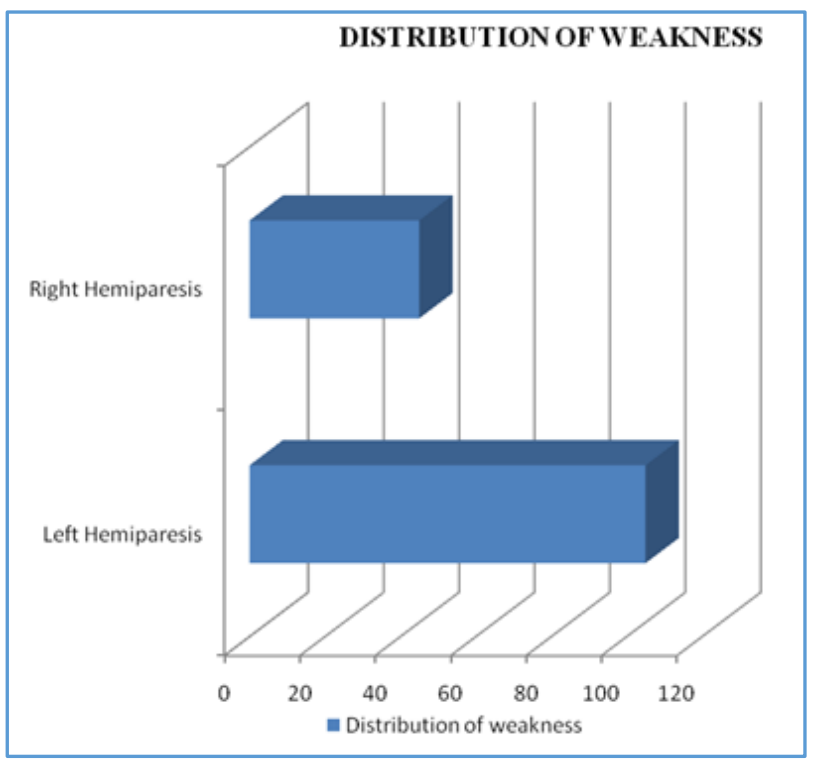

Figure 6. Pattern of Weakness

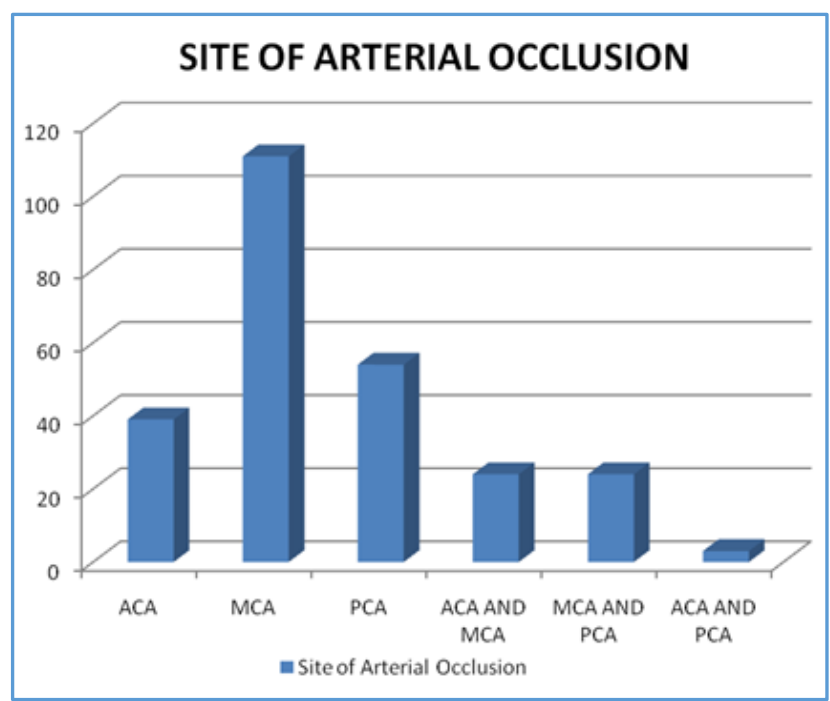

Figure 7. Site of Arterial Occlusion 


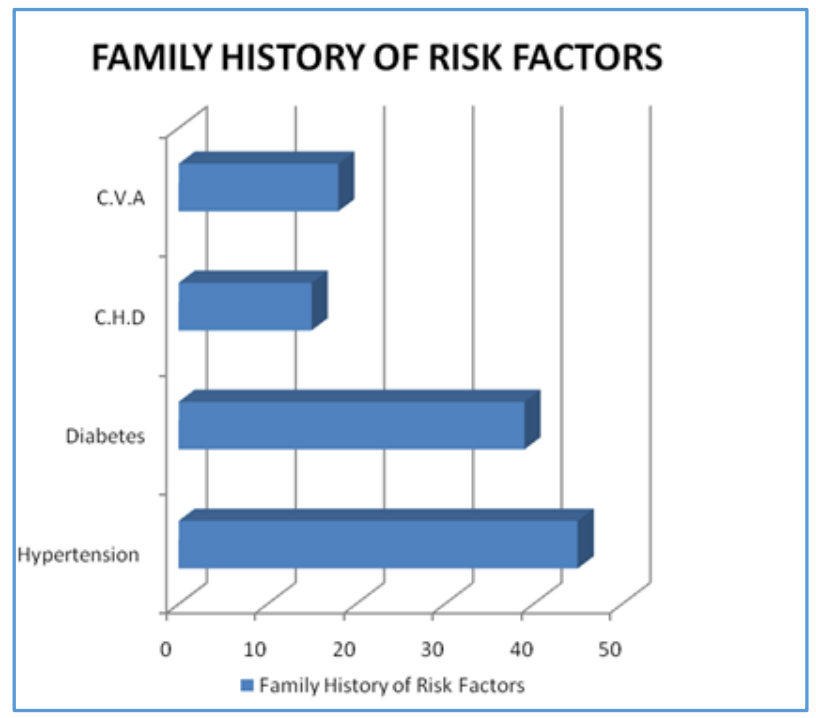

Figure 8. Family History of Risk Factors

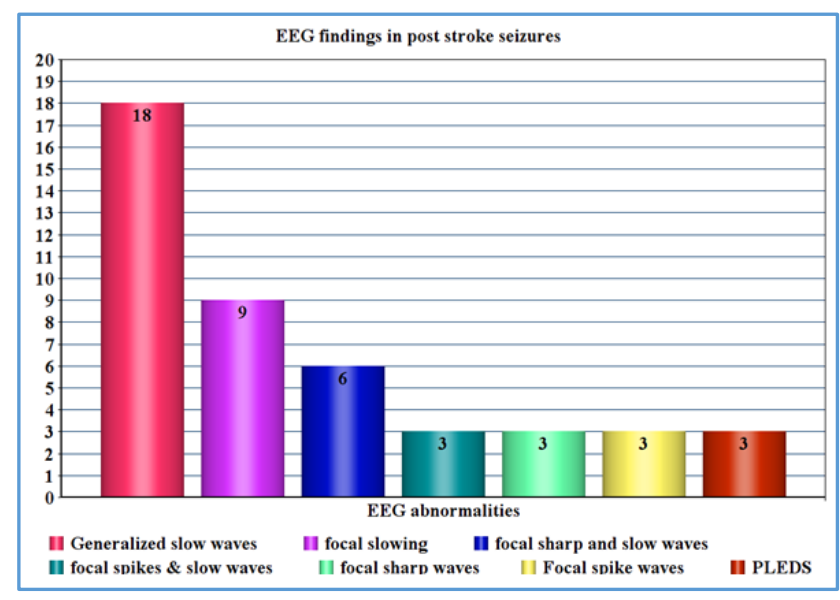

Figure 9. EEG Abnormalities in Post-Stroke Seizures

\section{DISCUSSION}

Ischaemic stroke manifests usually in the form of thrombotic stroke, embolic stroke, systemic hypoperfusion or venous thrombosis.[9] In case of severe or prolonged haemodynamic instability, focal and diffuse cerebral changes occur due to the effect of ischaemia, which is reversible or irreversible, depending on the degree and duration of blood flow. In ischaemic stroke, paradoxical increase of Cerebral Blood Flow (CBF) can be observed at the involved site and is known as luxury perfusion.[10]

Core ischaemic regions (blood flow $<15 \%$ ), penumbral regions (blood flow $<40 \%$ ) and extra-penumbral cortical regions (blood flow rate $>40 \%$ ) can result in both proximal and distal to arterial occlusion. This approximate flow based definition of core and of penumbra as well as extra-penumbral region is generally agreed upon.[11] Ischaemic penumbra generally occurs usually in the periphery of the brain when blood flow is reduced to cause hypoxia, but not very severe to cause irreversible failure of energy metabolism to cause cellular necrosis.[12] The margins of ischaemic area are hyperaemic with minimal or no parenchyma damage.

Hossmann summarised the threshold concept of pathophysiological changes in cerebral ischaemia. The inhibition in protein synthesis starts to deteriorate with the CBF less than $55 \mathrm{~mL} / 100 \mathrm{~g} / \mathrm{min}$. When CBF reduces to less than $35 \mathrm{~mL} / 100 \mathrm{~g} / \mathrm{min}$, increased glucose utilisation and lactate accumulation occurs. As CBF falls below $26 \mathrm{~mL} / 100$ $\mathrm{g} / \mathrm{min}$, the acidosis causes decline in phosphocreatine and adenosine triphosphate levels. At CBF around $23 \mathrm{~mL} / 100$ $\mathrm{g} / \mathrm{min}$, neurological dysfunction and suppression of electrical activity in the brain and evoked potentials occur. When CBF reaches to $5-18 \mathrm{~mL} / 100 \mathrm{~g} / \mathrm{min}$, irreversible hemiparesis and infarction occurs with terminal depolarisation, potassium efflux and calcium influx.[13]

The EEG is the recording of cerebral electrical activity measured over scalp due to the firing of neurons in the cerebral cortex. EEG records cumulated excitatory and inhibitory postsynaptic potentials in neuronal dendrites, usually in the superficial cerebral cortex. Deeper structures like the thalamus and brainstem produce potentials of low amplitude reflecting the functional status. Electrographic activity consists of spectrum of frequencies, i.e. physiological and pathological changes in cerebral function with delta (14 $\mathrm{Hz}$ ). Cerebral function on EEG show slower frequencies (delta and theta), produced by the thalamus and by cells in layers IIVI of cortex, while faster frequencies (alpha) from cells in layers III and V of cortex.[14]

In stroke, EEG represents changes of CBF fall.[15] EEG changes in cerebral ischaemia can be divided into four types based on cerebral blood flow. At CBF, $25-35 \mathrm{~mL} / 100 \mathrm{~g} / \mathrm{min}$, EEG shows reduction in amplitude of faster frequencies. As $\mathrm{CBF}$ reduces to $18-25 \mathrm{~mL} / 100 \mathrm{~g} / \mathrm{min}$, slowing of theta frequencies occurs. Further decrease of CBF to 12 - $18 \mathrm{~mL} / 100$ $\mathrm{g} /$ min causes marked suppression of frequencies. Suppression of all frequencies occurs with the reduction of $\mathrm{CBF}<8-10$ $\mathrm{mL} / 100 \mathrm{~g} / \mathrm{min}$ (Table 9).[16],[17] Murri et al showed that EEG is a highly sensitive tool for temporal, fronto-central and parietooccipital cortical-subcortical infarctions than for basal ganglia and internal capsule lesions.[18] EEG may supplement with imaging modalities for the diagnosis and prognosis in cerebral ischaemia.[19]

Animal models showed that EEG changes occur within 5 minutes of acute cerebral ischaemia, comparatively better than imaging techniques and clinical examination in a patient who is in altered level of consciousness or sedated. Periodic Lateralised Epileptiform Discharges (PLEDs) in EEG represent acute brain dysfunction or unilateral brain lesion, recorded in the area adjacent to cerebral infarction. ${ }^{20]}$ PLEDs were found to be associated with cerebral infarctions.[21] PLEDs in obtunded patients associated with focal seizures and focal neurological signs are usually transient and resolve spontaneously in 2 - 3 weeks. These discharges decrease in amplitude, repetition rate and then cease.[20]

Our study correlated with other studies of ischaemic stroke regarding age of onset, male predominance, risk factors, dyslipidaemia and family history of risk factors.[22],[23],[24] Our study showed that magnetic resonance imaging is a very sensitive and specific modality for detection of ischaemic stroke. ${ }^{[25]}$ Acutely ischaemic lesions demonstrate high signal of DWI (Diffusion Weighted Imaging) and low signal on ADC (Apparent Diffusion Coefficient) maps within minutes.[26] FLAIR images demonstrate abnormal signal sooner than T2WI and have been shown to detect infarcts within 3 hours after onset of acute stroke.[27] 


\section{CONCLUSION}

We put forward the following observations based on our study. Our study has limitations in accurate calculation of incidence due to sample size. Male predominance is observed. Elderly individuals are at increased risk of stroke. Comorbidities and lipid abnormalities increase the risk significantly. MRI is the most useful investigation for diagnosis and management in ischaemic stroke. Abnormal EEG and generalised slowing pattern observed specifically are associated with complications and mortality after acute ischaemic stroke. Larger infarct volume is associated with higher delta power in EEG. Generalised seizures and generalised slowing on EEG were common in patients who developed seizures after stroke. EEG gives significant information about acute stroke injury that can add to the information of structural brain imaging.

\section{REFERENCES}

1. U.S. Centers for disease control and prevention and the heart disease and stroke statistics. 2007. American Heart Association.http://www.strokecenter.org/patients/stats .htm.

2. Towfighi A, Saver JL. Stroke declines from third to fourth leading cause of death in the United States: historical perspective and challenges ahead. Stroke 2011;42(8):2351-5.

3. Mozaffarian D, Benjamin EJ, Go AS, et al. Heart disease and stroke statistics--2015 update: a report from the American Heart Association. Circulation 2015;131(4):e29-322.

4. The top 10 causes of death. WHO 2008.

5. Feigin VL, Forouzanfar MH, Krishnamurthi R, et al. Global and regional burden of stroke during 1990-2010: findings from the Global Burden of Disease Study 2010. Lancet 2014;383(9913):245-54.

6. Indian Heart Association Why South Asians Facts Web. May 8, 2015. http://indianheartassociation.org/whyindians-why-south-asians/overview/

7. Ellekjaer H, Holmen J, Indredavik B, et al. Epidemiology of stroke in Innherred, Norway, 1994 to 1996. Incidence and 30-day case-fatality rate. Stroke 1997;28(11):2180-4.

8. National Institute of Neurological Disorders and Stroke (NINDS) stroke: hope through research. National Institutes of Health. 1999.

9. Deb P, Sharma S, Hassan KM. Pathophysiologic mechanisms of acute ischemic stroke: an overview with emphasis on therapeutic significance beyond thrombolysis. Pathophysiology 2010;17(3):197-218.

10. Cho IH, Hayashida K, Kume N, et al. Visualization of pressure-dependent luxury perfusion in a patient with subacute cerebral infarction. Ann Nucl Med 1998;12(4):217-20.

11. Lipton P. Ischemic cell death in brain neurons. Physiol Rev 1999;79(4):1431-568.
12. Paciaroni M, Caso V, Agnelli G. The concept of ischemic penumbra in acute stroke and therapeutic opportunities. Eur Neurol 2009;61(6):321-30.

13. Frykholm P. Cerebral ischemia studied with PET and microdialysis. Comprehensive Summaries Uppsala Dissertations 2002;1157: P. 72. ISBN 91-554-5319-5328.

14. Rijsdijk M, Leijten FSS, Slooter AJC. Continuous EEG monitoring in the Intensive Care Unit. Neth J Crit Care 2008;12(4):157-62.

15. Wang J, Chen L, Wu B, et al. Correlation study of cerebral blood flow and EEG feature based on $\mathrm{CO} 2$ stimulation. Proc Intl Soc Mag Reson Med 2010;18:1.

16. Schneider AL, Jordan KG. Regional attenuation without delta (RAWOD): a distinctive EEG pattern that can aid in the diagnosis and management of severe acute ischemic stroke. Am J Electroneurodiagnostic Technol 2005;45(2):102-17.

17. Diedler J, Sykora M, Bast T, et al. Quantitative EEG correlates of low cerebral perfusion in severe stroke. Neurocrit Care 2009;11(2):210-6.

18. Murri L, Gori S, Massetani R, et al. Evaluation of acute ischemic stroke using quantitative EEG: a comparison with conventional EEG and CT scan. Neurophysiol Clin 1998;28(3):249-57.

19. Nuwer MR, Arnadóttir G, Martin NA, et al. Comparison of quantitative electroencephalography, computed tomography and behavioral evaluations to localize impairment in patients with stroke and transient ischemic attacks. J Neuroimaging 1994;4(2):82-4.

20. Andraus ME, Andraus CF, Alves-Leon SV. Periodic EEG patterns: importance of their recognition and clinical significance. Arq Neuropsiquiatr 2012;70(2):145-51.

21. Dan YF, Pan ABS, Lim SH. Periodic lateralized epileptiform discharges: aetiology and association with EEG seizures. Neurology Asia 2004;9(Suppl 1):107-8.

22. Grau AJ, Weimar C, Buggle F, et al. Risk factors, outcome and treatment in subtypes of ischemic stroke: the German stroke data bank. Stroke 2001;32(11):2559-66.

23. Allen CL, Bayraktutan U. Risk factors for ischaemic stroke. Int J Stroke 2008;3(2):105-16.

24. Tei H, Uchiyama S, Ohara K, et al. Deteriorating ischemic stroke in 4 clinical categories classified by the Oxfordshire community stroke project. Stroke 2000;31(9):2049-54.

25. González RG. Clinical MRI of acute ischemic stroke. Journal of Magnetic Resonance Imaging 2012;36(2):259-71.

26. Oppenheim C, Logak M, Dormont D, et al. Diagnosis of acute ischaemic stroke with fluid-attenuated inversion recovery and diffusion-weighted sequences. Neuroradiology 2000;42(8):602-7.

27. Noguchi $K$, Ogawa $T$, Inugami $A$, et al. MRI of acute cerebral infarction: a comparison of FLAIR and T2weighted fast spin-echo imaging. Neuroradiology 1997;39(6):406-10. 